\title{
Agenesis of the superior vena cava
}

INSERM

\section{Source}

INSERM. (1999). Orphanet: an online rare disease and orphan drug data base. Agenesis of the superior vena cava. ORPHA:99114

Agenesis of the superior vena cava (SVC) is a rare congenital anomaly of the great veins characterized by unilateral or bilateral complete absence of the SVC. Unilateral agenesis is mainly asymptomatic (most of the time diagnosed incidentally) and patients usually have otherwise normal heart structure. Bilateral agenesis, however, is frequently associated with other congenital cardiac anomalies and/or conduction abnormalities (such as tetralogy of Fallot, atrial septal defect) and typically present symptoms of SVC syndrome. 